See discussions, stats, and author profiles for this publication at: https://www.researchgate.net/publication/321698518

\title{
Meta-Analysis of the Sources of Bleeding after Adult Cardiac Surgery
}

Article in Journal of Cardiothoracic and Vascular Anesthesia · December 2017

DOI: 10.1053/j.jvca.2017.12.024

CITATIONS

8

8 authors, including:

(a)

Fausto Biancari

University of Turku

416 PUBLICATIONS 7,507 CITATIONS

SEE PROFILE

Tuomas O Kiviniemi

University of Turku

128 PUBLICATIONS 1,606 CITATIONS

SEE PROFILE

Some of the authors of this publication are also working on these related projects:

CAREAVR View project

Gyrocardiography View project
Q. Eeva-Maija Kinnunen 38 PUBLICATIONS 248 CITATIONS

SEE PROFILE

uomas Tauriainen

Oulu University Hospital

31 PUBLICATIONS 93 CITATIONS

SEE PROFILE 
Elsevier Editorial System(tm) for Journal of Cardiothoracic and Vascular Anesthesia

$$
\text { Manuscript Draft }
$$

Manuscript Number: JCVA-D-17-00794

Title: Meta-analysis of the Sources of Bleeding after Adult Cardiac Surgery

Article Type: Original Research Article

Keywords: Coronary artery bypass; cardiac surgery; bleeding; resternotomy, re-exploration, surgical source.

Corresponding Author: Professor Fausto Biancari, M.D., Ph.D.

Corresponding Author's Institution: University of oulu

First Author: Fausto Biancari, M.D., Ph.D.

Order of Authors: Fausto Biancari, M.D., Ph.D.; Eeva-Maija Kinnunen, MD, PhD; Tuomas Kiviniemi, MD, PhD; Tuomas Tauriainen, MS; Vesa Anttila, MD, PhD; Juhani K.E. Airaksinen, MD, PhD; Debora Brascia, MD; Francesco Vasques, MD 
Prof. J.A. Kaplan

Oulu October 23, 2017

Editor-in-Chief,

Journal of Cardiothoracic and Vascular Anesthesia

Dear Editor,

we would grateful if you would consider the attached article entitled: "Meta-analysis of the

Sources of Bleeding after Adult Cardiac Surgery" for possible publication in The Journal of Cardiothoracic and Vascular Anesthesia.

The article is original and data unpublished. The authors state that they do not have any conflicts of interest related with this study.

Best regards

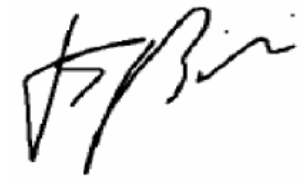

Prof. Fausto Biancari, on behalf of the other co-authors. 


\title{
Meta-analysis of the Sources of Bleeding after Adult Cardiac Surgery
}

Short title: Surgical bleeding after cardiac surgery

Fausto Biancari, ${ }^{\mathrm{a}, \mathrm{b}, \mathrm{c}} \mathrm{MD}, \mathrm{PhD}$, Eeva-Maija Kinnunen, ${ }^{\mathrm{b}} \mathrm{MD}, \mathrm{PhD}$, Tuomas Kiviniemi, ${ }^{\mathrm{c}}$ MD, PhD, Tuomas Tauriainen, ${ }^{b}$ MS, Vesa Anttila, ${ }^{c}$ MD, PhD, Juhani K.E. Airaksinen, ${ }^{\mathrm{c}} \mathrm{MD}, \mathrm{PhD}$, Debora Brascia, ${ }^{\mathrm{a}} \mathrm{MD}$, and Francesco Vasques, ${ }^{\mathrm{d}} \mathrm{MD}$

${ }^{\mathrm{a}}$ Department of Surgery, University of Turku, Turku, Finland;

${ }^{\mathrm{b}}$ Department of Surgery, University of Oulu, Oulu, Finland;

${ }^{c}$ Heart Center, Turku University Hospital and University of Turku, Turku, Finland;

${ }^{\mathrm{d}}$ Department of Anesthesia, Padua University Hospital, Padua, Italy.

Article word count: 3559 words

\section{Financial support}

This research did not receive any specific grant from funding agencies in the public, commercial, or not-forprofit sectors.

\author{
For correspondence: \\ Prof. Fausto Biancari, \\ Heart Center, \\ Turku University Hospital, \\ Hämeentie 11, PL 52, 20521 Turku, Finland \\ Tel.: +358 407333973 \\ E-mail: faustobiancari@yahoo.it
}




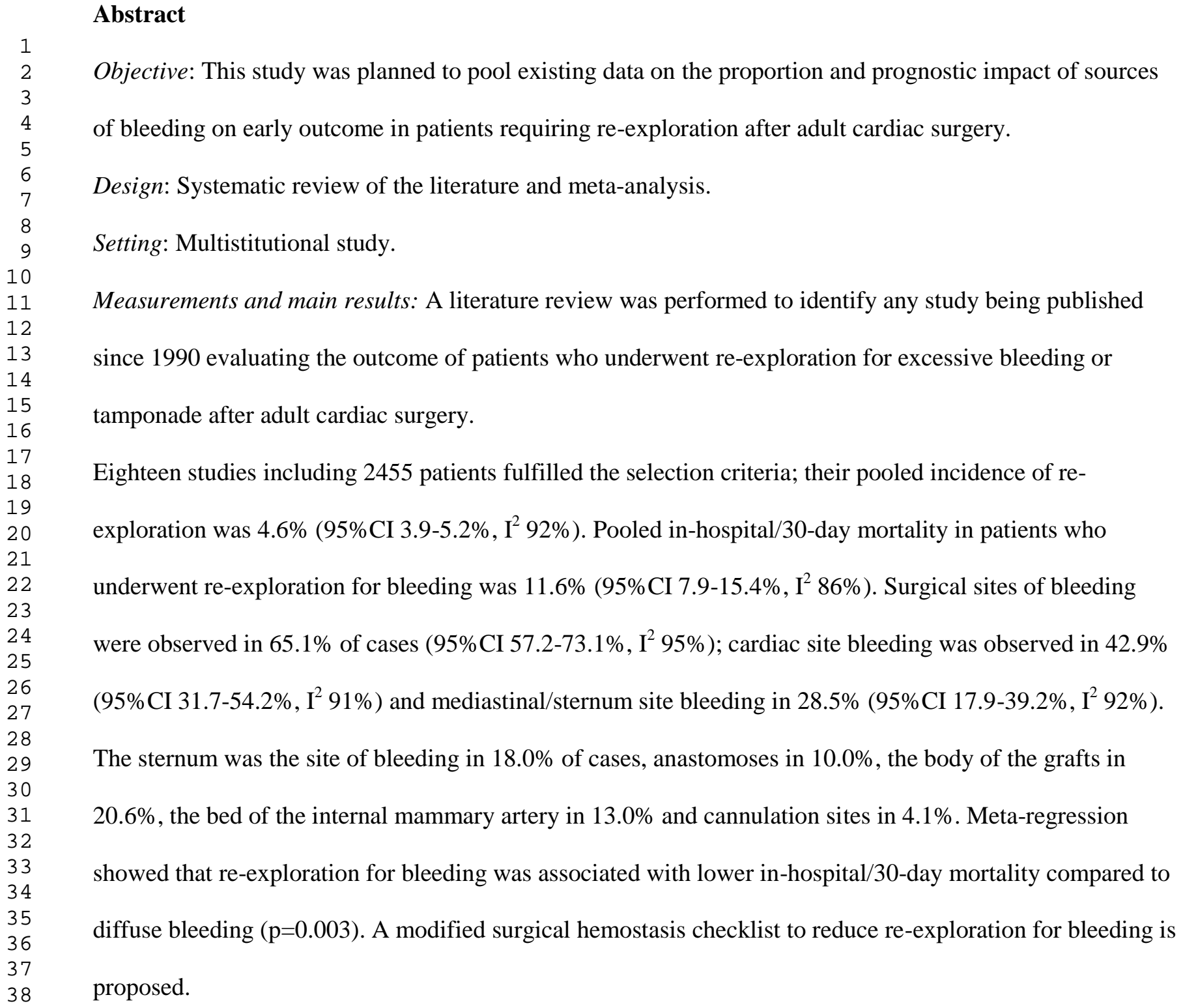

Conclusions: Surgical site bleeding is observed in two-thirds of patients undergoing re-exploration after adult cardiac surgery. Meticulous surgical technique and systematic intraoperative checking of potential surgical sites of bleeding is expected to reduce the risk of such a severe complication.

\section{Abstract word count: 250 words}

Keywords: Coronary artery bypass; cardiac surgery; bleeding; resternotomy, re-exploration, surgical source. 


\begin{abstract}
Introduction
Excessive bleeding requiring re-exploration is associated with poor outcome, ${ }^{1}$ and significant incremental costs. $^{2}$ In general, re-exploration is part of the spectrum of severe and massive perioperative blood loss requiring large amount of blood transfusion. ${ }^{3}$ A significant variability of severe blood loss and re-exploration for bleeding has been observed at institutional ${ }^{4}$ and individual surgeon's level. ${ }^{5,6}$ These observations suggest that perioperative bleeding may be related to differences in surgical skills and in the management of perioperative bleeding. Since a number of reoperations are secondary to technical factors, ${ }^{7}$ there is a need to estimate the proportion and types of surgical sites of bleeding as a means to reduce such a severe complication. Furthermore, knowledge of the nature of perioperative bleeding may be of importance in studies evaluating the efficacy and harms of antithrombotic drugs. The aim of the present meta-analysis is to investigate the sources of bleeding after adult cardiac surgery and their impact on early outcome.
\end{abstract}

\title{
Methods
}

The present systematic review and meta-analysis is registered in the International prospective register of systematic reviews PROSPERO with the reference code

\section{Search Strategy}

A literature review was performed through PubMed, Scopus, ScienceDirect and Google Scholar on August 2017 , to identify any study being published since 1990 evaluating the outcome of patients who underwent reexploration for excessive bleeding or tamponade after adult cardiac surgery. The retrieval terms were "reexploration", "resternotomy", "reoperation", "bleeding” combined with "cardiac surgery" OR "coronary artery bypass”. Once the abstracts of potentially relevant studies were scrutinized, each study was independently evaluated by three investigators (_) for inclusion or exclusion from this analysis. Reference lists of retrieved articles were searched as well. The guidelines for Preferred Reporting Items for Systematic reviews and Meta-Analyses (PRISMA) were applied. ${ }^{8}$ 


\section{Treatment Definition and Inclusion/Exclusion Criteria}

For the purpose of this analysis, eligible studies were those reporting on the sources of bleeding in patients who underwent re-exploration for excessive bleeding or tamponade after adult cardiac surgery. Studies that met the Population, Interventions, Comparison and Outcomes (PICO) criteria (Tab. 1) were included in the present meta-analysis.

To enter this analysis, studies had to fulfil all these inclusion criteria: (1) provide data on patients who underwent re-exploration for excessive bleeding or tamponade after any adult cardiac surgery procedure; (2) include patients aged 18 years or older; (3) report data on the type of bleeding, i.e. diffuse or surgical bleeding; (4) be a prospective or retrospective observational investigation; (5) be published in English language as a full article; (6) include at least 10 patients who underwent reoperation; and (7) be published since 1990.

Articles were ineligible for study inclusion if they (1) reported ambiguous or inaccurate data (discrepancies between data reported in the text and tables); (2) did not provide any information on the type of bleeding; (3) data was reported only in abstracts; (4) reported data on other than cardiac surgery interventions; (5) and/or included pediatric patients (6).

\section{Data Extraction}

Data was independently retrieved by three investigators ( $\square$. Disagreement on collected data was settled by consensus between these investigators. No attempt was made to obtain specific or missing data from the authors. The following data were extracted and collected on a dedicated datasheet: first author, year of publication, study period, overall number of adult cardiac surgery procedures performed during the study period, number of re-explorations for bleeding and tamponade type of intervention, patients' age, gender, major comorbidities, sources of bleeding, in-hospital/30-day mortality and stroke. Types of bleeding were classified as surgical sources of bleeding or diffuse bleeding/undetermined origin. Surgical sources of bleeding were further classified as cardiac sources when bleeding was from cardiac structures and/or bypass grafts. 
Sources of bleeding were defined as mediastinal when bleeding originated from vessels of the pericardium or external to pericardium, i.e. vessels of the sternum, neck and diaphragm. The quality of the included studies was assessed by two investigators using the National Heart, Lung, and Blood Institute (NHLBI) criteria for study quality assessment of case-control series (https://www.nhlbi.nih.gov/healthpro/guidelines/in-develop/cardiovascular-risk-reduction/tools/case_series; accessed on January 17, 2017).

\section{Outcomes}

The primary outcome of this study was the nature of bleeding, i.e. diffuse bleeding or any bleeding originating from one or more surgical sites. Patients having concomitant surgical site bleeding and diffuse bleeding, were categorized as having surgical bleeding. The secondary outcome was in-hospital/30-day postoperative mortality.

\section{Statistical Analysis}

Statistical analysis was performed using the Open Meta-Analyst software (Brown University, Providence, RI, USA; http://www.cebm.brown.edu/openmeta/). To control for the anticipated heterogeneity among observational studies, absolute values and means were pooled using random effects models. Heterogeneity across studies was evaluated using the $\mathrm{I}^{2}$ test. The results are expressed as untransformed proportions and means with their $95 \%$ confidence intervals (CI). Leave-one-out sensitivity analysis was performed to confirm consistency of the overall analysis. The impact of risk factors on in-hospital/30-day mortality was evaluated by meta-regression analysis. A p $<0.05$ was considered statistically significant. 


\section{Results}

Eighteen studies including 2455 patients ${ }^{5,9-25}$ fulfilled the pre-specified selection criteria and were included in this analysis (Fig. 1). Characteristics and main data reported in these studies are summarized in Table 2. Three studies ${ }^{5,10,21}$ were considered of good quality according to the NHBLI criteria and reported in details all surgical sites of bleeding.

The pooled incidence of re-exploration was 4.6\% (95\%CI 3.9-5.2\%, I $\mathrm{I}^{2} 92 \%, 17$ studies, 51497 patients) (Fig. 2). Pooled in-hospital/30-day mortality in patients who underwent re-exploration for bleeding was $11.6 \%$ (95\%CI 7.9-15.4\%, I² 86\%, 15 studies, 1763 patients).

Surgical sites of bleeding were observed in $65.1 \%$ of cases (95\%CI 57.2-73.1\%, $\mathrm{I}^{2}$ 95\%, 18 studies, 2455 patients) (Fig. 3). Cardiac site bleeding was observed in $42.9 \%$ of cases (95\% CI 31.7-54.2\%, $\mathrm{I}^{2}$ 91\%, 9 studies, 788 patients) and mediastinal/sternum site bleeding in $28.5 \%$ of cases (95\%CI $17.9-39.2 \%, \mathrm{I}^{2} 92 \%, 9$ studies, 882 patients). In particular, the sternum was the site of bleeding in $18.0 \%$ of cases (95\% CI 12.6$23.5 \%, \mathrm{I}^{2} 86 \%, 9$ studies, 1509 patients), anastomosis site in $10.0 \%$ of cases (95\%CI 5.3-14.6\%, $\mathrm{I}^{2} 91 \%, 10$ studies, 1603 patients), the body of the grafts in $20.6 \%$ of cases (95\%CI $12.9-28.2 \%, \mathrm{I}^{2} 79 \%, 8$ studies, 976 patients), the bed of the internal mammary artery in $13.0 \%$ of cases (95\% CI $8.1-17.9 \%, \mathrm{I}^{2} 74 \%, 6$ studies, 887 patients) and cannulation site in $4.1 \%$ of cases (95\% CI 1.8-6.4\%, $\mathrm{I}^{2} 79 \%, 10$ studies, 1130 patients).

Meta-regression showed that the rate of re-exploration for bleeding was not associated with increased early mortality $(\mathrm{p}=0.146)$. Higher prevalence of isolated coronary artery bypass grafting was associated with lower risk of in-hospital/30-day death $(\mathrm{p}=0.007)$. Furthermore, meta-regression showed that re-exploration for surgical site bleeding was associated with lower in-hospital/30-day mortality ( $\mathrm{p}=0.003$ ) (Fig. 4). This finding was confirmed also when two outliers with early mortality $>20 \%$ were excluded from the analysis $(\mathrm{p}=0.003)$. 


\section{Discussion}

There is a burden of evidence on the negative prognostic impact of re-exploration for excessive bleeding on the outcome after adult cardiac surgery, ${ }^{1,9}$ but less clear are the factors underlying this severe complication. Preoperative antithrombotic drugs and certain patient characteristics are thought to be the major determinants of severe postoperative bleeding. ${ }^{26}$ Identification of patients with bleeding diathesis is a cornerstone of pointof-care management of perioperative bleeding, but there is a lack of evidence of its efficacy in reducing the risk of re-exploration for excessive bleeding. ${ }^{27}$ Indeed, preoperative thromboelastometry may fail to predict severe bleeding due to surgical site bleeding. ${ }^{25}$ The results of this pooled analysis suggest that severe bleeding indicating reoperation for surgical hemostasis is related to surgical site bleeding in two-thirds of patients undergoing adult cardiac surgery. Several studies included in this analysis indicated that these bleeding sites are more frequently from cardiac structures/vascular grafts than mediastinal/sternal vessels. Sites of insertion of temporary pace-maker wires and of chest tubes may account for less frequent causes of excessive bleeding. ${ }^{5,10,28}$ These findings suggest that most of severe bleeding events can be prevented by a meticulous surgical technique and systematic checking of potential sites of bleeding. After having observed that severe bleeding originated mostly from surgical sites,${ }^{16}$ Loor et al. ${ }^{7}$ introduced a checklist for a systematic intraoperative evaluation of potential surgical sources of bleeding. These authors demonstrated that the use of this hemostasis checklist, which guides surgeons through a systematic checking of potential bleeding sites (cannulation sites, anastomoses, aortotomies, atriotomies, ventriculotomies, thymus, pericardium, mammary artery bed and sternum), significantly reduced the risk of re-exploration for bleeding. These authors did not assess whether this approach might have reduced also the chest drain output and the amount of blood transfusion. However, re-exploration for excessive bleeding is part of a spectrum of severe and massive bleeding occurring immediately after surgery or later on as a manifestation of retained blood syndrome. ${ }^{29}$ Indeed, the individual surgeon's impact on the risk of re-exploration seems to correlate with the amount of postoperative blood loss. ${ }^{5}$ Therefore, we may expect that meticulous surgical hemostasis may contribute also to an overall reduction of perioperative blood loss. 
These observations indicate that a surgical hemostasis checklist as proposed originally by Loor and colleagues $^{7}$ may be a valid means to reduce severe postoperative bleeding. Since available studies on this topic brought knowledge on further potential sites of bleeding, we modified Loor and colleagues' checklist by adding body of vascular grafts, epicardial pace-maker insertion sites, drainage insertion sites and neck vessels as surgical sites requiring systematic checking (Tab. 3).

The lack of individual patient data does not allow an accurate analysis of factors associated with increased risk of operative mortality in patients undergoing re-exploration for bleeding. However, meta-regression analysis of this aggregate data suggests that increased prevalence of isolated coronary artery bypass grafting was associated with lower risk of in-hospital/30-day mortality $(\mathrm{p}=0.007)$. This finding can be explained by the more complex nature of procedures other than isolated coronary surgery. Meta-regression showed also that reexploration for surgical site bleeding was associated with lower in-hospital/30-day mortality compared to diffuse or indeterminate bleeding $(\mathrm{p}=0.003)$. This observation suggests that identification of a surgical source of bleeding is associated with prompt surgical hemostasis and a more favorable outcome. On the contrary, surgical and pharmacological treatment for diffuse bleeding is far more complex and may be associated with residual blood loss and large amount of blood transfusion. Furthermore, coagulopathy resulting in diffuse bleeding is often related to the use of potent antithrombotic drugs in acute coronary syndrome and this may account for the higher mortality risk of these patients. ${ }^{30}$

This pooled analysis has a number of limitations. First, most of the retrieved studies were of retrospective nature and surgical site bleeding was not the primary outcome of these analyses. Second, surgical site bleeding might occur in presence of diffuse bleeding, but these cases were not clearly reported in the original studies. For the sake of simplicity and because of limited specific data, these patients were categorized as having surgical bleeding. However, it is unclear whether surgical site bleeding associated with diffuse bleeding carries an even worse prognosis than diffuse bleeding alone. Third, the available data does not clarify whether a number of surgical sites of bleeding were due to perioperative coagulopathy, to failure of surgical technique or a combination of both of these factors. The latter may significantly bias the real nature of perioperative bleeding. Finally, the available studies did not evaluate the prognostic impact of surgical site bleeding versus 
diffuse bleeding on early postoperative outcome. Therefore, the present finding of lower operative mortality in patients with surgical site bleeding compared to those with diffuse bleeding should be viewed within the limits of any regression analysis of aggregate data.

\section{Conclusions}

Surgical site bleeding is observed in two-thirds of patients undergoing re-exploration after adult cardiac surgery. Meticulous surgical technique and systematic intraoperative checking of potential surgical sites of bleeding is expected to reduce the risk of such a severe complication.

\section{Financial support}

This study was not financially supported 


\section{References}

1. Biancari F, Mikkola R, Heikkinen J, et al. Estimating the risk of complications related to re-exploration for bleeding after adult cardiac surgery: a systematic review and meta-analysis. Eur J Cardiothorac Surg 2012;41:50-5.

2. Alström U, Levin LÅ, Ståhle E, et al. Cost analysis of re-exploration for bleeding after coronary artery bypass graft surgery. Br J Anaesth 2012;108:216-22.

3. Dyke C, Aronson S, Dietrich W, et al. Universal definition of perioperative bleeding in adult cardiac surgery. J Thorac Cardiovasc Surg 2014;147:1458-63.

4. Karkouti K, Wijeysundera DN, Beattie WS, et al. Variability and predictability of large-volume red blood cell transfusion in cardiac surgery: a multicenter study. Transfusion 2007;47:2081-8.

5. Biancari F, Mikkola R, Heikkinen Jet al. Individual surgeon's impact on the risk of re-exploration for excessive bleeding after coronary artery bypass surgery. J Cardiothorac Vasc Anesth 2012;26:550-6.

6. Dixon B, Reid D, Collins M, et al. The operating surgeon is an independent predictor of chest tube drainage following cardiac surgery. J Cardiothorac Vasc Anesth 2014;28:242-6

7. Loor G, Vivacqua A, Sabik JF 3rd, et al. Process improvement in cardiac surgery: development and implementation of a reoperation for bleeding checklist. J Thorac Cardiovasc Surg 2013;146:1028-32.

8. Moher D, Liberati A, Tetzlaff J, et al. Preferred reporting items for systematic reviews and meta-analyses: the PRISMA statement. Ann Intern Med 2009;151:264-9.

9. Fröjd V, Jeppsson A. Reexploration for bleeding and its association with mortality after cardiac surgery. Ann Thorac Surg 2016;102:109-17.

10. Unsworth-White MJ, Herriot A, Valencia O, et al. Resternotomy for bleeding after cardiac operation: a marker for increased morbidity and mortality. Ann Thorac Surg 1995;59:664-7.

11. Kim DJ, Shin YC, Kim DJ, et al. The safety of resternotomy in the intensive care unit for postcardiotomy bleeding control. J Card Surg 2016;31:672-6.

12. Lopes CT, Brunori EH, Santos VB, et al. Predictive factors for bleeding-related re-exploration after cardiac surgery: A prospective cohort study. Eur J Cardiovasc Nurs 2016;15:e70-7. 
13. Ozolina A, Strike E, Nikitina-Zake L, et al. Polymorphisms on PAI-1 and ACE genes in association with fibrinolytic bleeding after on-pump cardiac surgery. BMC Anesthesiol 2015;15:122.

14. Čanádyová J, Zmeko D, Mokráček A. Re-exploration for bleeding or tamponade after cardiac operation. Interact Cardiovasc Thorac Surg 2012;14:704-7.

15. Kristensen KL, Rauer LJ, Mortensen PE, et al. Reoperation for bleeding in cardiac surgery. Interact Cardiovasc Thorac Surg 2012;14:709-13.

16. Vivacqua A, Koch CG, Yousuf AM, et al. Morbidity of bleeding after cardiac surgery: is it blood transfusion, reoperation for bleeding, or both? Ann Thorac Surg 2011;91:1780-90.

17. Okonta K, Rajan S. Re-exploration after open heart surgery at the Madras Medical Mission, Chennai, India. J West Afr Coll Surg 2011;1:1-17.

18. Gwozdziewicz M, Olsak P, Lonsky V. Re-operations for bleeding in cardiac surgery: treatment strategy. Biomed Pap Med Fac Univ Palacky Olomouc Czech Repub 2008;152:159-62.

19. Choong CK, Gerrard C, Goldsmith KA, et al. Delayed re-exploration for bleeding after coronary artery bypass surgery results in adverse outcomes. Eur J Cardiothorac Surg 2007;31:834-8

20. Karthik S, Grayson AD, McCarron EE, et al. Reexploration for bleeding after coronary artery bypass surgery: risk factors, outcomes, and the effect of time delay. Ann Thorac Surg 2004;78:527-34.

21. Hall TS, Brevetti GR, Skoultchi AJ, et al. Re-exploration for hemorrhage following open heart surgery differentiation on the causes of bleeding and the impact on patient outcomes. Ann Thorac Cardiovasc Surg 2001;7:352-7.

22. Sellman M, Intonti MA, Ivert T. Reoperations for bleeding after coronary artery bypass procedures during 25 years. Eur J Cardiothorac Surg 1997;11:521-7.

23. Sethi GK, Copeland JG, Goldman S, et al. Implications of preoperative administration of aspirin in patients undergoing coronary artery bypass grafting. Department of Veterans Affairs Cooperative Study on Antiplatelet Therapy. J Am Coll Cardiol 1990;15:15-20.

24. Chu MW, Wilson SR, Novick RJ, et al. Does clopidogrel increase blood loss following coronary artery bypass surgery? Ann Thorac Surg 2004;78:1536-41. 
25 Ghavidel AA, Toutounchi Z, Shahandashti FJ, et al. Rotational thromboelastometry in prediction of bleeding after cardiac surgery. Asian Cardiovasc Thorac Ann 2015;23:525-9.

26. Biancari F, Brascia D, Onorati F, et al. Prediction of severe bleeding after coronary surgery: the WILLBLEED Risk Score. Thromb Haemost 2017;117:445-56.

27. Serraino GF, Murphy GJ. Routine use of viscoelastic blood tests for diagnosis and treatment of coagulopathic bleeding in cardiac surgery: updated systematic review and meta-analysis. Br J Anaesth 2017;118:823-33.

28. Bougioukas I, Jebran AF, Grossmann M, et al. Is there a correlation between late re-exploration after cardiac surgery and removal of epicardial pacemaker wires? J Cardiothorac Surg 2017;12:3.

29. Boyle EM Jr, Gillinov AM, Cohn WE, et al. Retained blood syndrome after cardiac surgery: a new look at an old problem. Innovations (Phila) 2015;10:296-303.

30. Biancari F, Airaksinen KE, Lip GY. Benefits and risks of using clopidogrel before coronary artery bypass surgery: systematic review and meta-analysis of randomized trials and observational studies. J Thorac Cardiovasc Surg 2012;143:665-75. 


\section{Legends to figures}

Figure 1. Literature search flowchart.

Figure 2. Forest plot of re-exploration for excessive bleeding after adult cardiac surgery.

Figure 3. Forest plot of surgical site of bleeding after adult cardiac surgery.

Figure 4. Meta-regression plot on the impact of rate of surgical site of bleeding and early mortality. 
Table 1. Participants, intervention, comparison and outcomes (PICO) of the present meta-analysis.

\begin{tabular}{ll}
\hline PICO & Description \\
\hline Population & Patients who underwent adult cardiac surgery \\
Intervention & Re-exploration for excessive bleeding or tamponade after adult cardiac surgery \\
Comparison & None \\
Outcomes & Sources of bleeding, in-hospital/30-day mortality, stroke \\
\hline
\end{tabular}


Table 2. Characteristics and data of the included studies.

\begin{tabular}{lccccccccc}
\hline \multicolumn{1}{c}{ Author } & $\begin{array}{c}\text { Year of } \\
\text { publication }\end{array}$ & $\begin{array}{c}\text { Type of } \\
\text { study }\end{array}$ & $\begin{array}{c}\text { NHLBI } \\
\text { quality } \\
\text { rating }\end{array}$ & $\begin{array}{c}\text { No. of } \\
\text { patients }\end{array}$ & $\begin{array}{c}\text { Re-exploration } \\
\text { rate }(\%)\end{array}$ & $\begin{array}{c}\text { Isolated } \\
\text { CABG } \\
(\%)\end{array}$ & $\begin{array}{c}\text { Urgent / } \\
\text { emergency } \\
\text { procedure } \\
(\%)\end{array}$ & $\begin{array}{c}\text { Surgical } \\
\text { site } \\
\text { bleeding } \\
(\%)\end{array}$ & $\begin{array}{c}\text { In- } \\
\text { hospital } \\
30 \text {-day } \\
\text { mortality } \\
(\%)\end{array}$ \\
\hline Sethi & & & & & & & & & \\
Unsworth-White & 1990 & $\mathrm{P}$ & Fair & 36 & 4.7 & 100 & 0.0 & 38.9 & - \\
Sellman & 1995 & $\mathrm{R}$ & Fair & 85 & 3.8 & 42.4 & - & 70.6 & 22.4 \\
Hall & 1997 & $\mathrm{R}$ & Fair & 378 & 4.4 & 73.8 & - & 85.7 & 5.8 \\
Karthik & 2001 & $\mathrm{R}$ & Good & 82 & 3.6 & - & - & 67.1 & 9.8 \\
Chu & 2004 & $\mathrm{R}$ & Fair & 89 & 3.1 & 100 & 29.2 & 82.0 & 4.5 \\
Choong & 2004 & $\mathrm{P}$ & Fair & 11 & 3.5 & 100 & 100 & 0.0 & - \\
Gwozdziewicz & 2007 & $\mathrm{P}$ & Fair & 191 & 5.9 & 55.0 & 36.1 & 78.0 & 11.0 \\
Okonta & 2008 & $\mathrm{R}$ & Fair & 98 & 2.3 & 63.3 & 15.3 & 54.1 & 11.2 \\
Vivacqua & 2011 & $\mathrm{R}$ & Fair & 342 & 3.4 & 74.3 & - & 61.1 & - \\
Biancari & 2011 & $\mathrm{R}$ & Fair & 285 & - & - & 80.7 & 79.6 & - \\
Čanádyová & 2012 & $\mathrm{R}$ & Good & 113 & 5.6 & 100 & 60.2 & 73.5 & 6.2 \\
Kristensen & 2012 & $\mathrm{R}$ & Fair & 152 & 3.4 & 38.8 & 42.8 & 55.3 & 37.5 \\
Ozolina & 2012 & $\mathrm{R}$ & Fair & 101 & 7.0 & 24.8 & 14.9 & 56.4 & 15.8 \\
Ghavidel & 2012 & $\mathrm{P}$ & Fair & 11 & 12.5 & - & - & 81.8 & 0.0 \\
Fröjd & 2015 & $\mathrm{P}$ & Fair & 42 & 10.5 & 100 & 4.8 & 76.2 & 4.8 \\
Kim & 2016 & $\mathrm{R}$ & Fair & 320 & 5.9 & 36.9 & 23.4 & 67.2 & 7.5 \\
Lopes & 2016 & $\mathrm{R}$ & Fair & 101 & 3.7 & 32.7 & 29.7 & 67.3 & 16.8 \\
\hline & 2016 & $\mathrm{P}$ & Good & 18 & 5.6 & 33.3 & 0.0 & 83.3 & - \\
\hline
\end{tabular}

R: retrospective study; P: prospective study; CABG: coronary artery bypass grafting. 
Table 3. Modified checklist to prevent surgical site bleeding.

\begin{tabular}{l}
\hline Anatomical sites \\
\hline Cardiac sites \\
$\quad \square$ Cannulation sites \\
$\square$ Vascular anastomoses \\
$\quad \square$ Body of vascular grafts \\
$\square$ Aortotomies, atriotomies, ventriculotomies \\
$\square$ Epicardial pace-maker wires insertion site \\
Mediastinum \\
$\square$ Thymus \\
$\square$ Pericardium \\
$\square$ Neck \\
$\square$ Drain insertion sites \\
Chest wall \\
$\square$ Internal mammary artery bed \\
$\square$ Sternum
\end{tabular}


Figure 1

Click here to download high resolution image

1

2

3

4

5

6

8

9

10

11

12

13

14

15

16

17

18

19

20

21

22

23

24

25

26

27

28

29

30

31

32

33

34

35

36
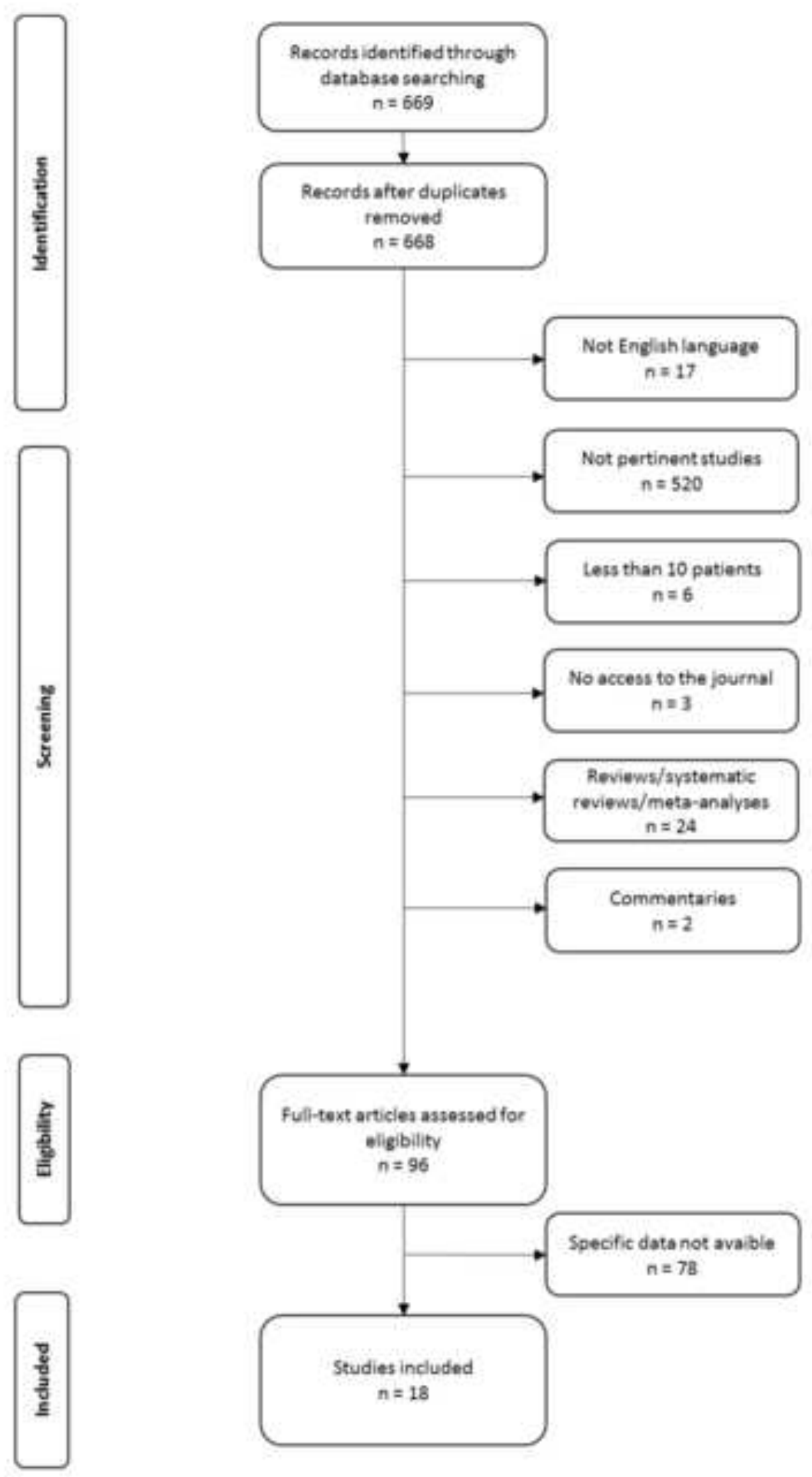


\section{Click here to download high resolution image}

1

2

3

5

6

7

8

9

10

11

Studies

Estimate 1950 C.1.)

$\mathrm{By} / \mathrm{Trt}$

\section{Sethi 1990}

Unsworth-White 1995

Sellman 1997

Hall 2001

Chu 2004

Karthik 2004

Choong 2007

Gwozdziewicz 2008

Okonta 2011

Biancari 2012

Canadyova 2012

Kristensen 2012

Ozolina 2012

Ghavidel 2015

Lopes 2016

Frojd 2016

Kim 2016

$0.047(0.032,0.062)$

$0.038(0.030,0.046)$

$0.044(0.040,0.048)$

$0.036(0.029,0.044)$

$0.035(0.015,0.056)$

$0.031,(0.024,0.037)$

$0.059(0.051,0.067)$

$0.023(0.018,0.027)$

$0.034(0.030,0.037)$

$0.056(0.046,0.067)$

$0.034(0.029,0.039)$

$0.070(0.056,0.083)$

$0.125(0.056,0.194)$

$0.105(0.075,0.135)$

$0.056(0.031,0.081)$

$0.059(0.053,0.066)$

$0.037(0.030,0.044)$

Overall $(1 \times 2=91.94 \%, p<0.001)$

$0.046(0.039,0.052)$

$2170 / 51497$

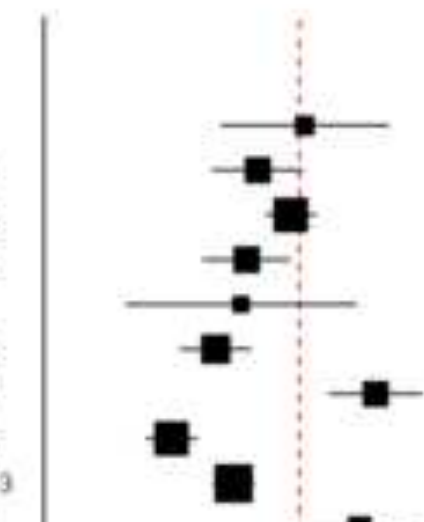

$113 / 2001$

$152 / 4493$

$101 / 1452$

$12 / 86$

$42 / 400$

$18 / 323$

$320 / 5392$

$101 / 2719$

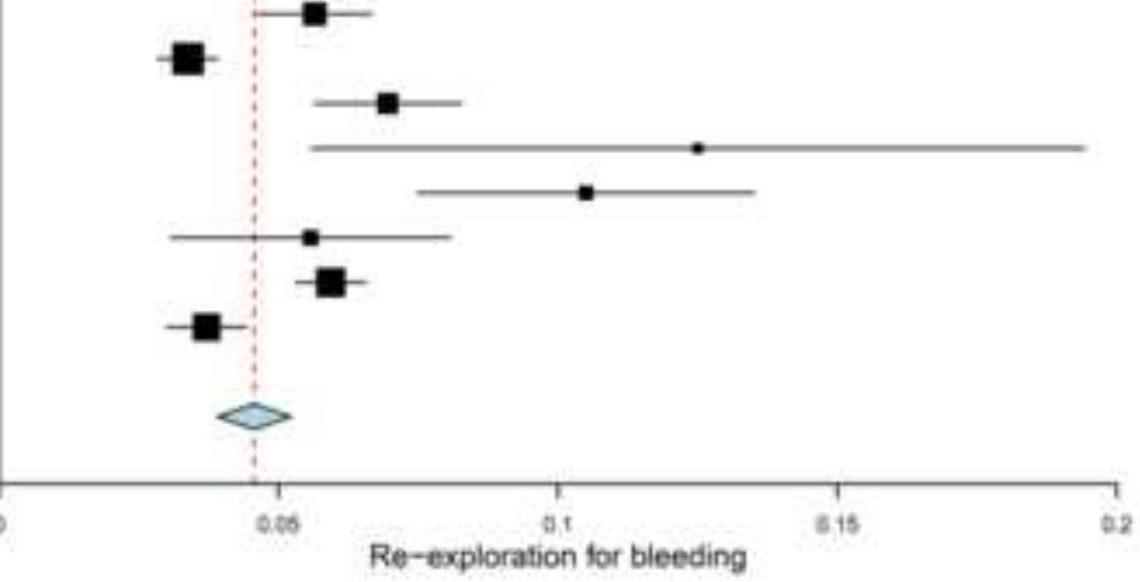




\section{Click here to download high resolution image}

1

2

3

6

9

10

11

12

13

14

15

16

17

18

19

20

21

22

23

24

25

26

27

28

29

30

31

32

33

34

35

36

37

38

39

40

41

42

43

44

45

46

47

\section{Studies}

Sethi 1990

Unsworth-White 1995

Seliman 1997

Hall 2001

Chu 2004

Karthik 2004

Choong 2007

Gwozdziewicz 2008

Okonta 2011

Vivacqua 2011

Biancari 2012

Cariadyova 2012

Kristensen 2012

Ozolina 2012

Ghavidel 2015

Lopes 2016

Frojd 2016

Kim 2016

Overall $\left(1^{\wedge} 2=94.98 \%, P<0.001\right)$ gutieate (95t C.I.) Ev/Trt

$0.389(0.230,0.548) \quad 14 / 36$

$0.706(0.609,0.803) \quad 60 / 85$

0.857 (0.822, 0.092) 324/37 है

$0.671(0.569,0.772) \quad 55 / 62$

$0.042(0.000,0.155) \quad 0 / 11$

$0.920(0.740,0.900) \quad 72 / 89$

$0.780(0.721,0.839) \quad 149 / 191$

$0.541(0.442,0.639) \quad 53 / 98$

$0.512(0.459,0.565) \quad 175 / 342$

$0.796(0.750 ; 0.843) \quad 227 / 285$

$0.735(0.653,0.816) \quad 83 / 213$

$0.553(0.474,0.632) \quad 34 / 152$

$0.564(0.468,0.661) \quad 57 / 101$

$0.82 \mathrm{H}(0.590,2.000) \quad 9 / 11$

$0.762(0.633,0.691) \quad 32 / 42$

$0.833(0.661,1.000) \quad 15 / 18$

$0.672(0.620,0.723) \quad 215 / 320$

$0.673(0.582,0.765) \quad 68 / 201$
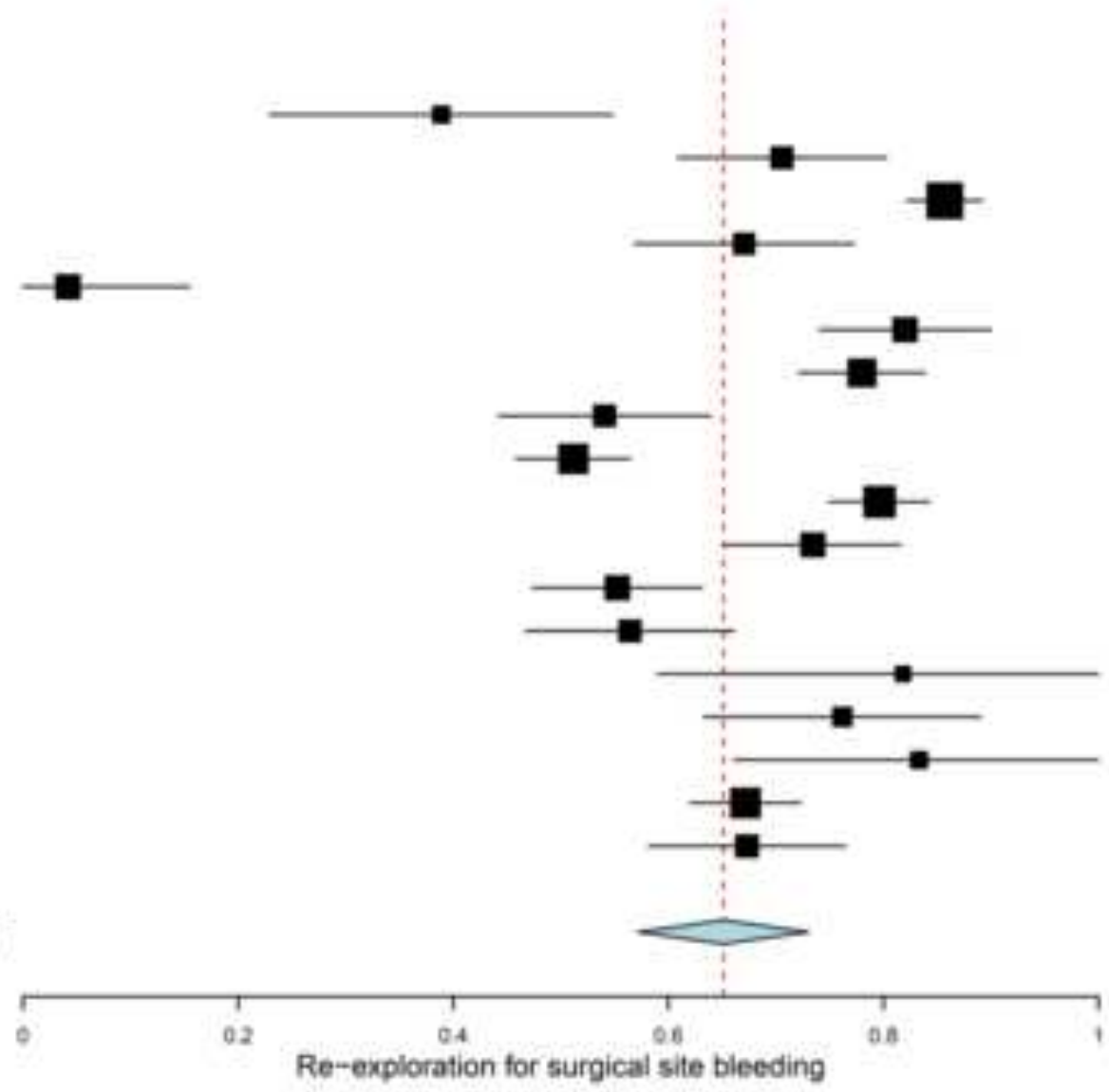

Re-exploration for surgical site bleeding 
Figure 4
Click here to download high resolution image

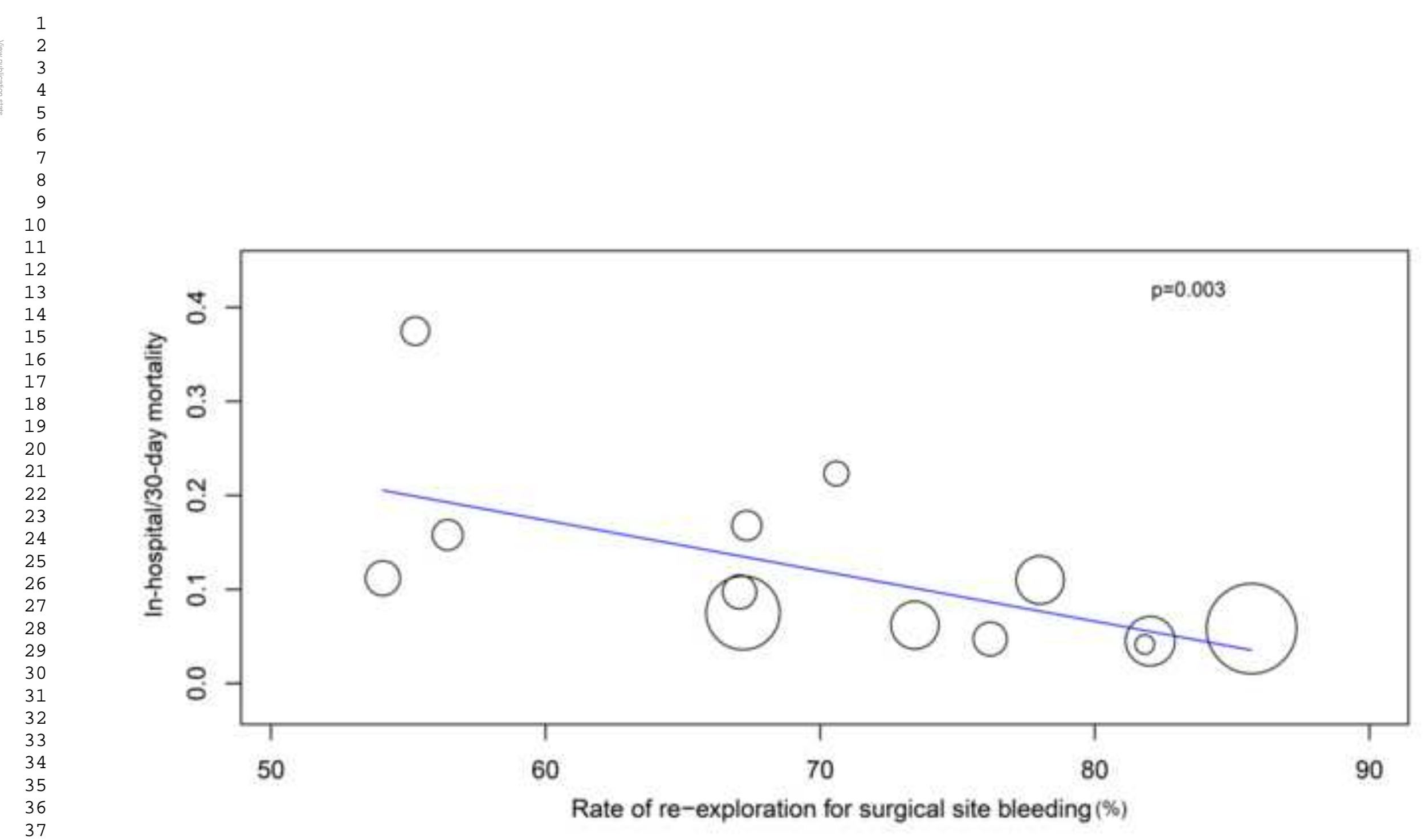

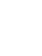

